\title{
CONFLITOS SOCIAIS NA EUROPA: UMA PAZ IMPOSSÍVEL?
}

\section{Resumo}

\section{Leila Bijos*}

Análise dos movimentos sociais na França e na América Latina, num contexto de ausência de programas políticos de inserção de imigrantes. Por meio da violência, os jovens manifestantes expressam seu inconformismo com o desemprego, o fracasso escolar e outros sintomas da discriminação de que se julgam vítimas, inclusive por parte da polícia. A passagem do estado de natureza até o estado social produz no homem uma mudança bem acentuada, substituindo, em sua conduta, o instinto pelo sentimento de justiça, e outorgando a suas ações relações morais que antes estavam ausentes.

À medida que a repressão se intensifique, fica ainda mais difícil a percepção da realidade. A França, como sociedade pode converter-se em uma ameaça a si própria ao não combinar integração e diferenças socioeconômicas, superando a oposição entre um modelo republicano e um comunitarismo carregado de agressividade.

A América Latina vivenciou uma longa era de repressão militar, de violência, oprimida por um Estado distante dos indivíduos; incapaz de suprí-los com políticas públicas e sociais.

Na sociedade civil é onde surgem e se desenvolvem os conflitos econômicos, sociais, ideológicos, religiosos, que as instituições públicas têm o dever de equacionar.

Palavras-chaves: Autoritarismo; Repressão; Movimentos Sociais; Relações de Dominação; Teoria Política;

* Doutora em Sociologia, pela Universidade de Brasília (CEPPAC/UnB), Coordenadora do Curso de PósGraduação em Relações Internacionais com ênfase em Cooperação Internacional e professora da graduação do curso de Relações Internacionais do UniCEUB. 


\section{INTRODUÇÃO}

T.H. Green said in 1881, "that freedom, rightly understood, is the greatest of blessings; that its attainment is the end of all our effort as citizens! Whether or not we "all" agree with so exacting a claim, it is hard to deny that ideas of freedom influence us deeply. We have reason to value our own freedom, and it is difficult to think of the excellence or the limitations of a society, or of the rightness or wrongness of social arrangements, without invoking - in one way or another - freedoms of various kinds and their fulfillment and violation in the societies under scrutiny".

Amartya Sen, Rationality And Freedom.

Ao analisarmos o conceito de guerra e paz, inferimos sobre o direito natural, tendo Grotius como o primeiro a aplicar o direito natural nas relações internacionais, ou seja, num campo que até então nunca fôra submetido a qualquer regulamentação. Através dos princípios de um direito natural preexistente ao Estado, de um Estado baseado no consenso, de subordinação do poder executivo ao poder legislativo, de poder limitado, de direito de resistência, conforme exposto na teoria do Estado liberal de John Locke, o que respalda aos cidadãos sua incorporação numa sociedade de direitos.

Incorporar-se como membro participativo na sociedade nos remonta a Hobbes, que debate o contrato social, como um pacto em favor de terceiro, é firmado entre os indivíduos, com o objetivo de preservarem suas vidas, transferem a outrem não-partícipe (homem ou assembléia) todos os seus poderes - não há, ainda, que se falar em direitos, pois estes só aparecem com o Estado. Ou seja: para pôr fim à guerra, despojam-se do que possuem em troca da segurança do Leviatã ${ }^{1}$.

Streck e Morais (2004: 38) ressaltam que "contrapondo Hobbes, para Locke o poder estatal é essencialmente um poder delimitado. O erro do soberano não será a fraqueza, mas o excesso. E, em conseqüência, por isso, admite o direito de resistência. A soberania absoluta, incontrastável, do primeiro cede passo à teoria do pai do individualismo liberal, na qual ainda consta o controle do Executivo pelo Legislativo e o controle do governo pela sociedade (cernes do pensamento liberal)”.

Já no terceiro contratualista - Jean Jacques Rousseau - há um deslocamento da noção de soberania. Para chegar naquilo que Rousseau denominou de contrato social, é fundamental que se compreenda o estado de natureza e a inserção do homem em

${ }^{1}$ A respeito do tema, ver: Bolzan de Morais, José Luis. Ainda Hobbes. Revista da Faculdade de Direito da URI/FW. Frederico Westphalen: EDURI, 1999. 
comunidade. Com efeito, o estado de natureza em Rousseau é somente uma categoria histórica para facilitar esse entendimento. Assim, no "Discurso sobre a desigualdade", Rousseau diz que "o verdadeiro fundador da sociedade civil foi o primeiro que, depois de haver delimitado um terreno, pensou em dizer 'isto é meu', e falou a outros, tão ingênuos para nele acreditarem". A desigualdade nasceu, pois, junto com a propriedade, e, com a propriedade, nasce a hostilidade entre os homens. Com isso se percebe a visão pessimista de Rousseau sobre a história, ao ponto de Voltaire ter classificado o Discurso sobre a origem e os fundamentos da desigualdade entre os homens como sendo um "libelo contra o gênero humano".

Ao contrário de Hobbes, Rousseau não considera o homem como "o lobo do homem"; na verdade, o homem se transforma no lobo do homem no decorrer da história. É fácil perceber, assim, que o estado de natureza rousseauniano é antitético ao de Hobbes: "Tudo é bom quando sai das mãos do Autor das coisas", porém "tudo se degenera nas mãos do homem”, sentencia. Conseqüentemente, no seu Contrato Social, Rousseau diz que o homem nasceu livre, e, paradoxalmente, encontra-se aprisionado. Rousseau pretende, assim, devolver a liberdade ao homem, e o modelo que propõe se sustenta na consciência humana e deve estar aberto à comunidade: “A passagem do estado de natureza até o estado social produz no homem uma mudança bem acentuada, substituindo, em sua conduta, o instinto pelo sentimento de justiça, e outorgando a suas ações relações morais que antes estavam ausentes" (Streck e Morais, 2004: 38-39).

Por ser fundamento racional, a teoria do direito natural ligava-se como vimos, às doutrinas dos jurisconsultos da Antiguidade. Concordava, igualmente, com o espírito dos pensadores do século XVII e mais ainda com os pensadores do século XVIII. Nessa época, preocupações de caráter social e político vieram acentuar as tendências individualistas que as teorias racionalistas traziam em germe. O termo "política" foi transmitido por influência da obra do eminente Aristóteles, intitulada Política, que, na verdade, deve ser considerada o primeiro tratado sobre a natureza, as funções, as divisões do Estado, e sobre as várias formas de governo, predominantemente no significado de arte ou ciência do governo. O conceito de política, entendida como forma de atividade ou práxis humana, está estreitamente ligado ao conceito de poder. No capítulo X de o Leviatã, Hobbes enfatiza que o poder foi definido tradicionalmente como "consistente 
nos meios para se obter alguma vantagem", o que é corroborado por Bertrand Russel em sua obra Power: A New Social Analysis, mostrando que um desses meios é o domínio sobre outros homens (além do domínio sobre a natureza), o poder é definido ora como uma relação entre dois sujeitos, na qual um impõe ao outro a própria vontade, e foram exatamente essas manifestações de ódio, o instinto de justiça, a explosão de descontentamento que presenciamos na França durante o mês de novembro de 2005. Os descendentes de imigrantes árabes e africanos que vivem na França levaram o país à pior onda de violência social desde a rebelião juvenil de maio de 1968. No dia 8 de novembro de 2005, um aposentado de 61 anos foi espancado até a morte por um adolescente. Os holofotes da mídia passaram a apresentar ininterruptamente os veículos, as escolas, creches, lojas e estúdios em chamas, em meio a um plano de emergência lançado pelo Ministro Villepin para conter a violência "de maneira firme e justa". Villepin ressaltou, também, as reformas educacionais e medidas para combater o desemprego, apontado como um dos combustíveis dos protestos. Por meio da violência, os jovens manifestantes expressam seu inconformismo com o desemprego, o fracasso escolar e outros sintomas da discriminação de que se julgam vítimas, inclusive por parte da polícia. Os jovens amotinados por um contingente de 8 mil soldados mobilizados especialmente para esse fim, declaram "guerra" às autoridades e gritam contra a polícia, mas o alvo principal de sua ira é o ministro do Interior, Nicholas Sarkozy, que nos primeiros dias dos distúrbios se referiu aos manifestantes como "escória".

Do ponto de vista do sociólogo Alain Touraine², "a sociedade francesa, incapaz há 10 anos de mudar seu modelo cultural", vive "uma fase de desintegração, marcada pela rejeição dos grupos minotários", que "se fecham numa defesa comunitarista e recorrem cada vez mais à violência”. O sociólogo enfatiza que esta situação é mais marcante na França do que em outros países europeus, como Itália e Alemanha, e que os franceses não foram capazes de operar a mudança desse modelo. À medida que a repressão se intensifique, fica ainda mais difícil a percepção da realidade, a França, como sociedade pode converter-se em uma ameaça a si própria, se não combinar integração e diferenças, superando a oposição entre um modelo republicano e um comunitarismo carregado de agressividade.

\footnotetext{
${ }^{2}$ Ver: Alain Touraine. Palavra e sangue: política e sociedade na América Latina, Campinas, Unicamp/Trajetória Cultural: 1989.
} 
Os protestos dos imigrantes na França alastram-se como pólvora, incendiando os países vizinhos da Bélgica, da Alemanha, podendo atingir a Itália.

No que concerne ao Brasil, o país acolhe hoje cerca de 3 mil refugiados, vindos de 55 países, de acordo com depoimento de António Guterres, alto comissário das Nações Unidas para Refugiados (ACNUR) ${ }^{3}$. Num mundo com crescente intolerância e medo, no qual o populismo desencadeia uma enorme confusão nas opiniões públicas entre refugiados, migrações, terrorismo.

\section{ANSEIOS POR UM MODELO INTEGRACIONISTA E DE SOCIABILIDADE}

A cidadania pressupõe a existência de uma comunidade política nacional, na qual os indivíduos são incluídos, compartilhando um sistema de definições, de crenças, com relação aos poderes públicos, à própria sociedade e ao conjunto de direitos e deveres que são atribuídos aos cidadãos. Nesse sentido, aceitar ou não refugiados, é um assunto complexo, que pode implicar em quebra de soberania. Ao serem aceitos por uma determinada nação, passam a fazer parte de uma comunidade política, com direitos plenos. Ser cidadão consiste em acreditar, em estar imbuído de sentimento patriótico, é vincular-se ativamente às causas públicas. A cidadania é a dimensão pública dos indivíduos, que separa o Estado da sociedade, e vê os indivíduos isolados e competitivos na dimensão particular, mas integrados e cooperativos na comunidade política. Neste sentido, a cidadania pressupõe um modelo de integração e de sociabilidade (Fleury, 1999, cit. por Ardaya, 2001: 12-13), o que não está ocorrendo com os imigrantes franceses, que se sentem discriminados e alijados do processo democrático, com menos propensão para o modelo de riqueza e bem-estar. Como partícipes de uma comunidade política moderna, os cidadãos devem ser inseridos num processo de construção democrática permanente, que legitime seus direitos e deveres. Entre eles, encontra-se a eliminação da pobreza.

Como membros de uma comunidade política moderna os cidadãos devem ser inseridos num processo de construção democrática permanente, que legitime seus direitos e deveres. Entre eles, encontra-se a eliminação da pobreza. A pobreza, como um fenômeno complexo, tem muitas dimensões e os pobres enfrentam muitos constrangimentos no acesso

\footnotetext{
${ }^{3}$ Ver: Correio Braziliense, Mundo, 8.11.2005.
} 
aos mercados sociais, à educação e a outros serviços sociais indispensáveis. Ao compararmos as características socioeconômicas dos pobres e não-pobres, inferimos que a maioria dos pobres não tem acesso à educação básica, são dependentes dos produtos primários na agricultura para a sua sobrevivência, não possuem propriedade ou terra para o cultivo e o sustento de suas famílias, além de sobreviverem com uma renda ínfima.

Os efeitos maléficos da globalização estão incidindo sobre a vida dos cidadãos. Esta tendência é evidenciada pelas migrações. Muitas famílias estão deixando seus países de origem, deixando as áreas rurais para aventurarem-se na busca de melhores chances nos centros urbanos, enfrentando uma série de constrangimentos, já que são incapazes de encontrar um emprego no setor formal da economia, no qual, conseqüentemente, não terão renda suficiente para comprar um imóvel, sendo obrigados a viver com o mínimo de estrutura física ou social; sem estradas, escolas, telefones, rádios, lojas, e clínicas médicas, dessa forma, a sua capacidade para usufruírem das oportunidades de mercado torna-se reduzida (Bijos, 2005: 100-101).

A sociedade civil é o lugar onde surgem e se desenvolvem os conflitos econômicos, sociais, ideológicos, religiosos, que as instituições públicas têm o dever de equacionar através da mediação ou através da repressão.

Sujeitos desses conflitos e portanto da sociedade civil, exatamente enquanto contraposta ao Estado, são as classes sociais, ou mais amplamente, os grupos, os movimentos, as associações, as organizações que as representam ou se declaram seus representantes; ao lado das organizações de classes, os grupos de interesse, as associações de vários gêneros com fins sociais, e indiretamente políticos, os movimentos de emancipação de grupos étnicos, de defesa dos direitos civis, de libertação da mulher, os movimentos de jovens, etc.

$\mathrm{Na}$ América Latina surgem, a cada dia, em número sempre crescente, frentes populares e organizações de base, que funcionam conjuntamente, ou de modo totalmente independente, aos partidos tradicionais das esquerdas. Como tem havido um processo crescente de alienação, acompanhado de uma perda total de confiança nas organizações políticas tradicionais, em face do desenvolvimento tecnológico capitalista, que se impõe sob formas diferentes mas em igual intensidade, tanto nos países desenvolvidos como nos subdesenvolvidos, esse desenvolvimento tem fortalecido e acelerado a divisão de trabalho predominante e uma relação de exploração, tanto da natureza como dos homens 
entre si. $\mathrm{Na}$ acepção de $\mathrm{Marx}^{4}$, essa classe oprimida e explorada dos países industrializados e dos países em desenvolvimento é englobada, geralmente, sob o conceito de proletariado, e têm sido reprimidos na sua criatividade social, na sua autonomia e nas formas de relacionamento solidário, e através de formas múltiplas de desqualificação e "expropriação" psíquica (Hirsch: 1980).

\section{SOBRE A GÊNESE DOS MOVIMENTOS SOCIAIS}

De acordo com Scherer-Warren e Krischke (1987: 24), "a composição social de um movimento é, por certo, sempre especificamente de classe, ainda que não represente uma única classe homogênea. Tanto assim, que pode chegar a ser um verdadeiro movimento de massas".

Os movimentos sociais não têm, necessariamente, a mesma estrutura organizativa de um partido, ou seja, não reconhecem militância formal nem capacidade hierarquizada de decisão. Nos países industriais avançados, apesar da difusão de uma tradição marxista vulgarizada, não se criou uma classe revolucionária compacta, com claras perspectivas sociais, que fosse a iniciadora e portadora de movimentos sociais nacionais. Dentre os mais relevantes movimentos sociais na América Latina, citamos o movimento operário democrático e popular surgido no Brasil, liderado por Luís Ignácio da Silva (Lula), e que logo derivou no Partido dos Trabalhadores; o Sandinismo, que surgiu na Nicarágua como um grande movimento social, de caráter pluriclassista e pluriideológico; as formas diferentes que assumem a luta popular no Peru, tanto ao nível dos bairros ("Pueblos Jóvenes”) como ao nível regional (Frentes Regionais para a Defesa dos Interesses do Povo); as novas experiências de "greves cívicas nacionais", com a participação de sindicatos, partidos políticos e organizações populares (grupos eclesiásticos de base, comitês de mulheres, grupos estudantis, culturais, etc.) no Equador, na Colômbia e no Peru; os movimentos de ocupações ilegais de terrenos em São Paulo; as invasões maciças de terras e fazendas pelos camponeses do México e do Brasil através do Movimento dos Trabalhadores Sem Terra (MST), e de outros países; as tentativas de autogestão nas favelas das grandes cidades como Caracas, Lima, Rio de Janeiro e São Paulo; os comitês

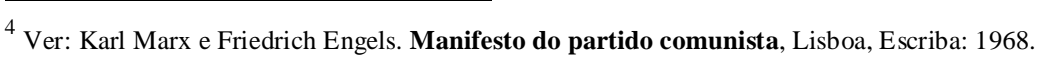


de defesa dos Direitos Humanos e as Associações de Familiares Presos e Desaparecidos, sendo estas duas últimas uniciativas surgidas basicamente dos movimentos sociais (Scherer-Warren e Krischke, 1987: 26).

A mobilização dos cidadãos na América Latina, especialmente das mulheres como mães, reivindicando melhorias básicas em suas comunidades rurais ou urbanas, envolvendo a vizinhança em encontros para discussão de temas como o alto custo de vida, a falta de água potável, eletricidade, meios de transporte, escolas, proporcionou a criação de padrões de cidadania coletiva, prospectando a consolidação da democracia.

De acordo com Jane Jaquette

a sociedade civil não se encontra mais em oposição ao Estado, mas novos laços de representatividade e de responsabilidade devem ser criados entre as associações civis, partidos políticos, e o executivo, para trabalharem - mesmo que isso seja interpretado como flexível - em prol de relações sociais igualitárias, onde existam normas de liderança e autoridade (1994, p. 223).

A criação, a manutenção e o desenvolvimento de relações sociais igualitárias, na acepção de Daniel Levine ${ }^{5}$ são essenciais para a democratização. Durkheim (1999) corrobora com o pensamento de Jaquette e de Levine, enfatizando que a sociedade é composta de um número infinito de indivíduos não-organizados, que um Estado hiperatrofiado é forçado a oprimir e conter, constitui uma verdadeira monstruosidade sociológica... Além do mais, o Estado está tão distante dos indivíduos; suas relações com eles são tão externas e intermitentes para penetrar profundamente nas consciências individuais e socializá-los interiormente. ... A nação só poderá ser mantida se, entre o Estado e o indivíduo se interpõe uma série completa de grupos secundários, que esteja perto o suficiente dos indivíduos, para atraí-los para sua esfera de ação e direcioná-los para o seu caminho, no âmago da corrente geral da vida social... Os grupos ocupacionais

\footnotetext{
${ }^{5}$ Ver: 1) LEVINE, Daniel H. Paradigm lost: dependence to democracy. World Politics 40, Apr. 1988, p. 389; 2) SCHIRMER, Jennifer. The seeking of truth and the gendering of consciousness: the comadres of El Salvador and the Conavigua Widows of Guatemala. In: RADCLIFFE, Sarah A.; WESTWOO, Sally (Eds.). Viva: women and popular protest in Latin America. London: Routledtge, 1993, p. 61.
} 
são perfeitos para desempenharem este papel, e este é o seu destino. Mas o que une a vida de grupos comunitários com as grandes estruturas da política nacional?

Numa análise de situações pós-conflito, e direcionando nosso foco para os países latino-americanos, verificamos que estes vivenciaram períodos longos de regime militar e uma transição para a democracia, como Argentina, Uruguai, Peru e Chile. As transições de certa forma se completaram, com exceção do Peru e dos movimentos "campesinos" na Bolívia. Muitas das instituições democráticas foram mantidas, e permaneceu o foco ou responsabilidade de como construir sociedades que possam sustentar instituições políticas democráticas e proporcionar algumas medidas para uma justiça social.

Essas instituições, especialmente as criadas por mulheres que sofreram a violência dos regimes militares, destacaram-se como movimentos de defesa da cidadania na década de 1970, fundadas por donas-de-casas de classe baixa, nas áreas urbanas (mujeres populares), em prol de políticas públicas e sociais, melhoramentos nos bairros, creches, postos de saúde, ou buscando maridos ou filhos desaparecidos, como as "Madres de la Plaza de Mayo" na Argentina, mulheres militantes na Colômbia, no Uruguai, Peru e Chile (com o governo e a queda de Salvador Allende em 1973). No Chile, as feministas ganharam influência trabalhando em prol de votos para o novo governo democrático, na época da disputa entre Augusto Pinochet e o candidato de oposição Patricio Aylwin em 1989, e antes no plebiscito de 1988.

Dentre as instituições mais importantes destacam-se: a Academia de Humanismo Cristiano, a Acción para la Liberración de la Mujer Peruana, Asociación de Mujeres Argentinas, Organización Feminista Argentina (OFA), Asociación de Mujeres Alfonsina Storni, Asociación de Mujeres Louisa Amanda Espinosa, Asociación de Mujeres Confrontando la Problematica Nacional (Nicarágua). Asociación de Educadores, Asociación para el Trabajo y el Estudio de la Mujer, Centro de Estudios para el Desarrollo de la Mujer (CEDEM), Centros de Madres (CEMAs), Cidadania, Estudos, Pesquisa, Informação e Ação (CEPIA), Centro Feminista de Estudos e Assessoria (CFEMEA) no Brasil.

Os movimentos em defesa da cidadania nas Américas, com a conseqüente criação de várias instituições, romperam com o silêncio que persistia acerca das violações dos direitos humanos, das perseguições e desaparecimentos forçados. Mazzuoli (2000) 
analisa essa temática, que só pode ser compreendida a partir da interação do Direito Interno e do Direito Internacional, à luz do princípio da dignidade humana. Defende o tratamento jurídico especial e diferenciado aos Tratados Internacionais de Proteção dos Direitos Humanos, que diversamente dos tratados tradicionais, apresentam hierarquia constitucional e incorporação automática.

Mazzuoli (2000) faz uma análise a partir do século XVIII, mostra o avanço do movimento iluminista, quando começa a ser definido o conceito de cidadania, como resultado da Revolução Francesa, quando surgiu a famosa Declaração dos Direitos do Homem e do Cidadão, de 1789, que sob a influência do discurso jurídico burguês, lançou as primeiras bases da idéia de "cidadão".

Nesse contexto, Trindade (1996) relata que a construção da moderna "cidadania" se insere no universo dos direitos humanos, e se associa de modo adequado ao contexto mais amplo das Relações entre os direitos humanos, a democracia e o desenvolvimento, com atenção especial ao atendimento das necessidades básicas da população de uma nova cultura de observância dos direitos humanos.

A criação da ONU, em 1945, e a promulgação da "Declaração Universal dos Direitos do Homem", em 1948, trouxeram, de forma definitiva, o problema dos direitos humanos com profundos reflexos na ordem interna das sociedades nacionais.

Assim, a partir da Declaração dos Direitos do Homem, uma série de instrumentos internacionais vieram à luz abordando os temas mais variados do elenco dos direitos inalienáveis da pessoa humana, cada um resultante de um movimento e de uma realidade política e histórica, todos, contudo, convergentes e, ao cabo, marcados pela indivisibilidade.

Trindade (1996) conclui então que o ponto central da questão dos direitos humanos, sobretudo no âmbito do Terceiro Mundo, concentra-se na efetividade dos mecanismos internacionais e internos de implementação desses direitos e no papel do Estado e das organizações não-governamentais, nessa questão. Tais direitos, têm como titular o indivíduo, a pessoa humana.

Com as declarações Americana dos direitos e deveres do homem e universal dos direitos humanos (1948) teve início a repulsa a tortura em todas as suas manifestações, como se lê no art. XVIII da declaração americana, quando se fala no direito à justiça, e no 
artigo V da declaração universal, onde se diz de forma explícita, que "ninguém será submetido a tortura, nem a tratamento ou castigo cruel, desumano ou degradante" (Convenção Contra a Tortura e Outros Tratamentos ou Penas Cruéis, Desumanos ou Degradantes (1984).

Dentre os iminentes analistas dos direitos humanos cita-se Dourado, 2001, Fraga, 2003, Gorenstein, 2002, Sábato, 1984, Pinheiros, 2001, Guimarães, 2001. Jaguaribe (1986) apresenta aspectos fundamentais da situação internacional da década de 80, a problemática Norte-Sul, problemas da América Latina e questões de ordem estratégica. Cervo (2001) na sua obra "Relações Internacionais da América Latina - Velhos e Novos Paradigmas", analisa os países latino-americanos de 1930 até os dias atuais. O argumento central de Cervo sobre a interpretação orgânica da história, é a existência de um destino comum que perseguiram os países desde os anos da depressão capitalista, uma vez configurados os espaços nacionais, os governos da região orientaram sua ação interna e eterna para a meta do desenvolvimento.

\section{CONCLUSÃO}

Diante dos protestos dos imigrantes na França, quando vêem à tona as diferenças sociais, a intolerância racial, vemos um conjunto de indivíduos que vivem dentro de um território delimitado e que está sujeito a um certo poder, sendo a soberania característica definidora desse poder. A sociedade civil se rebela quando ocorre uma ruptura entre as relações reais entre soberano e súditos. A injustiça social está inserida na superestrutura do Estado, com suas relações de dominação, que tenta conter os germes da desagregação existentes na sociedade civil.

No século XXI causa surpresa a existência de focos de conflitos na Europa, quando se imaginava um ciclo de paz, de desenvolvimento, de integração política e social, sob o manto capitalista da globalização. Questionadores da alienação, como Karl Deutsch (1982), da opressão, Hannah Arendt, do autoritarismo, decorrentes dos ciclos de ditadura na América Latina, algumas conclusões podem ser observadas.

Os ciclos de ditadura surgem quando as classes dominantes demonstram sua impotência em fazer frente às novas necessidades de desenvolvimento capitalista, quando 
o regime anterior passa a bloquear esse desenvolvimento. As forças armadas aparecem então como um verdadeiro partido político, capaz de agir rapidamente, matam, torturam e somem com os dissidentes. Nesse ínterim, surgem espontaneamente movimentos em defesa dos cidadãos. Na Europa, os novos movimentos sociais suscitam, sob vários ângulos e abordagens, a admiração e a surpresa de muitos pesquisadores - que se interrogam sobre o significado, as origens e objetivos dessas experiências de base, de autogestão e desalienação.

\section{REFERÊNCIAS BIBLIOGRÁFICAS}

ARDAYA, Gloria. Participación política y liderazgos de mujeres en Bolívia. La Paz: Centro de Información y Desarrollo de la Mujer (CIDEM); PROLID-BID, 2001.

BIJOS, Leila. Mulher e Desenvolvimento: O Programa de Microcrédito Regional para as Mulheres no Setor Informal Urbano: 1980 - 2002 - Um Estudo de Caso: Brasil-Bolívia (Tese de Doutorado), Centro de Pesquisa e Pós-Graduação Sobre as Américas - CEPPAC, Universidade de Brasilia, Brasília: 2005.

CERVO, Amado Luiz. Relações Internacionais da América Latina - Velhos e novos paradigmas, Brasília: IBRI, 2001.

DOURADO, Denisart. Tortura - Depoimento de um advogado criminalista, Leme: Editora de Direito, 2001.

DURKHEIM, Émile. Sociologia. São Paulo: Ática, 1999.

FRAGA, Thelma Araújo Esteves; MELLO, Cleyson de Moraes. Direitos Humanos Coletânea de legislação, Rio de Janeiro: Freitas Bastos, 2003.

GORENSTEIN, Fabiana; HIDAKA, Leonardo Jun Ferreira. Manual de Direitos Humanos Internacionais: acesso aos sistemas global e regional de proteção dos direitos humanos (org. Jayme Benvenuto Lima Jr.), São Paulo: Edições Loyola, 2002.

JAGUARIBE, Hélio. Novo Cenário Internacional, Rio de Janeiro: Guanabara Koogan, 1986.

JAQUETTE, Jane S. Conclusion: women's political participation and the prospects for democracy. In: JAQUETE, Jane S. (Ed.). The women's movement in Latin America: participation and democracy. $2^{\text {nd }}$. ed. Boulder, Colorado: Westview Press, 1994. p. 223-238.

HIRSCH, Joachim. “Proletariat Adieu?”, in Links, 122, Offenbach, 1980. 
HOBBES, T. Leviatã. In: Os Pensadores. São Paulo: Abril Cultural, 1988.

LEVINE, Daniel H. Paradigm lost: dependence to democracy. World Politics 40, Apr. 1988, p. 389.

MAZZUOLI, Valério de Oliveira. Direitos Humanos e Relações Internacionais, Campinas: Aga Juris, 2000.

MARX, Karl e ENGELS, Friedrich. Manifesto do partido comunista, Lisboa, Escriba, 1968.

MORAIS, José Luís Bolzan de. Ainda Hobbes. Revista da Faculdade de Direito da URI/FW. Frederico Westphalen: EDURI, 1999.

PINHEIRO, Paulo Sérgio; GUIMARÃES, Samuel Pinheiro. Direitos Humanos no Século XXI, Rio de Janeiro: IPRI, Fundação Alexandre de Gusmão, 1999.

ROUSSEAU, J. J. Do contrato social. In: Os Pensadores. São Paulo: Abril Cultural, 1983.

SABATO, Ernesto. Nunca Mais, Porto Alegre: L\&P Editores, 1984.

SCHERER-WARREN, Ilse e KRISCHKE, Paulo J. (Orgs.) Uma Revolução no cotidiano: os novos movimentos sociais na América Latina, São Paulo: Brasiliense, 1987.

SEN, Amartya. Rationality and Freedom. The Belknap Press of Harvard University, Cambridge, Massachusetts, 2002.

STRECK, Lenio Luiz e MORAIS, José Luis Bolzan. Ciência Política e Teoria Geral do Estado. $4^{\text {a }}$ edição, Livraria do Advogado Editora, Porto Alegre: 2004.

TOURAINE, Alain. Palavra e sangue: política e sociedade na América Latina, Campinas, Unicamp/Trajetória Cultural: 1989.

TRINDADE, Antônio Augusto Cançado. A Proteção Internacional dos Direitos Humanos, São Paulo: Editora Saraiva, 1991. 